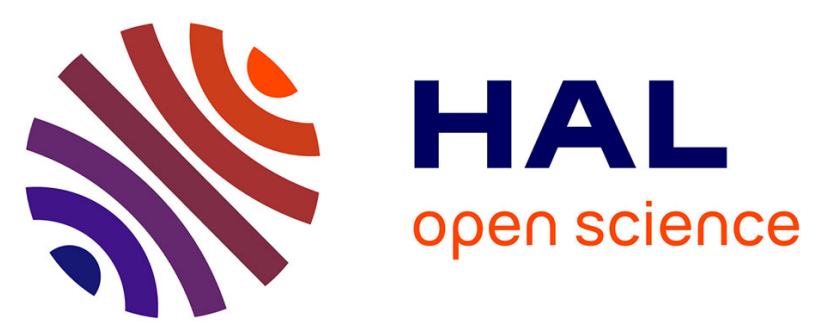

\title{
Collagen implants equipped with 'fish scale'-like nanoreservoirs of growth factors for bone regeneration
}

Sandy Eap, Alice Ferrand, Jessica Schiavi, Laetitia Keller, Tunay Kokten,

Florence Fioretti, Didier Mainard, Guy Ladam, Nadia Benkirane-Jessel

\section{- To cite this version:}

Sandy Eap, Alice Ferrand, Jessica Schiavi, Laetitia Keller, Tunay Kokten, et al.. Collagen implants equipped with 'fish scale'-like nanoreservoirs of growth factors for bone regeneration. Nanomedicine, 2014, 9 (8), pp.1253-1261. 10.2217/NNM.13.122 . hal-02337242

\section{HAL Id: hal-02337242 \\ https://hal.science/hal-02337242}

Submitted on 29 Oct 2019

HAL is a multi-disciplinary open access archive for the deposit and dissemination of scientific research documents, whether they are published or not. The documents may come from teaching and research institutions in France or abroad, or from public or private research centers.
L'archive ouverte pluridisciplinaire HAL, est destinée au dépôt et à la diffusion de documents scientifiques de niveau recherche, publiés ou non, émanant des établissements d'enseignement et de recherche français ou étrangers, des laboratoires publics ou privés. 


\section{Collagen implants equipped with 'fish scale'-like nanoreservoirs of growth factors for bone}

\section{regeneration}

Implants triggering rapid, robust and durable tissue regeneration are needed to shorten recovery times and decrease risks of postoperative complications for patients. Here, we describe active living collagen implants with highly promising bone regenerative properties. Bioactivity of the implants is obtained through the protective and stabilizing layer-by-layer immobilization of a protein growth factor in association with a polysaccharide (chitosan), within the form of nanocontainers decorating the collagen nanofibers. All components of the implants are US FDA approved. From both in vitro and in vivo evaluations, the sophisticated strategy described here should enhance, at a reduced cost, the safety and efficacy of the therapeutic implants in terms of large bone defects repair compared with current simplistic approaches based on the soaking of the implants with protein growth factor.

KEYWORDS: bone morphogenetic protein 2 bone regeneration collagen implant drug delivery layer-by-layer deposition regenerative nanomedicine

Bone has a capacity to regenerate after suffering partial damage. However, this regeneration becomes difficult when a serious break or tumor lesion occurs and the loss of tissue is substantial. Today, these cases are treated with various grafts with a number of disadvantages, such as limitations with donors. There is a demonstrated clinical need for alternatives of autologous fresh bone graft with excellent biological performance. Smart nanoengineered materials allow novel therapeutic modalities such as improved specific cell targeting by means of nanoparticle-based drugs, resulting in a decreased side effects for patients. Recently, nanomedicine has taken issue for drug delivery, gene delivery and regenerative medicine [1-4]. Other advances are being made in sophisticated biomaterials for use in less invasive surgical implantations, leading to shorter recovery times and decreased risk of postoperative infections or other complications. Such innovations will improve the quality of life, extend life expectancies and should reduce the overall cost of healthcare.

Biomaterials also play central roles in modern strategies in regenerative medicine and tissue engineering as designable biophysical and biochemical milieus that direct cellular behavior and function. Tissue engineering is an interdisciplinary field that has attempted to implement a variety of processing methods for synthetic and natural polymers to fabricate tissue and organ regeneration scaffolds. Such materials should provide provisional 3D supports to interact with cells in ways that control their function by guiding the spatially and temporally complex multicellular processes of tissue formation and regeneration [5-12]. The guidance provided by biomaterials may facilitate restoration of structure and function of damaged or dysfunctional tissues.

Several biomimicking medical devices for regenerative medicine have been inspired by the intricate fibrillar architecture of natural extracellular matrix (ECM) components [13]. Such matrices have already shown remarkable success in tissue-engineering applications [8,14], examples of which include reconstruction of a dog urinary bladder [13] and the regeneration after brain injury in a mouse stroke model [15]. However, it has been established that inert ECM mimetic scaffolds are not efficient at generating durable tissue repair. Therefore, there is a need for materials that ensure the sustained release of active compounds. To this end, recent advances in nanotechnology have led to various engineered ECM analogs and biomaterials incorporated with active compounds (drugs, genes or growth factors) within the form of layer-by-layer (LbL) coatings built-up from oppositely charged macromolecules [16-32].

As considerable effort is currently devoted to the design of nanostructured functional materials, ultrathin polyelectrolyte multilayer (PEM) coatings built-up from oppositely charged macromolecules constitute promising candidates, particularly in the field of biomaterials $[16,17,31,33]$. These supramolecular nanoarchitectures can not only specifically control cell activation, but

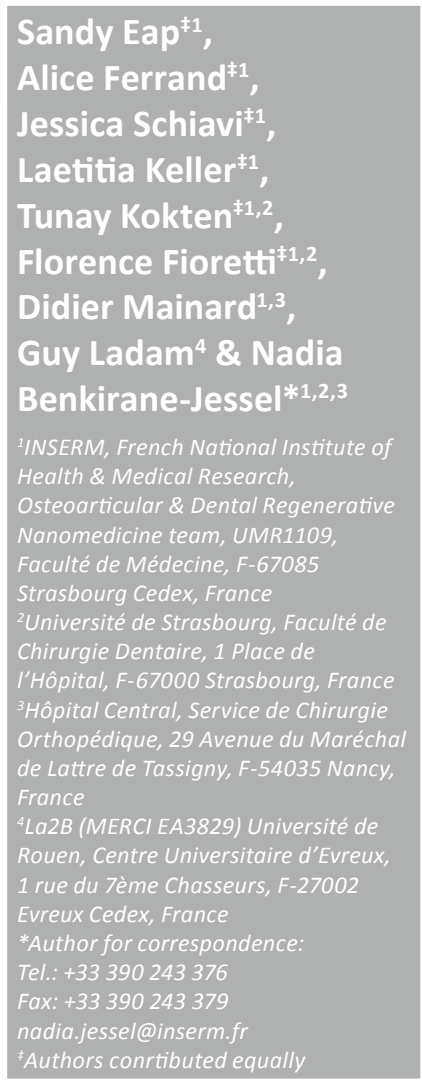

Future Medicine part of 
also mediate the local delivery of drugs, peptides, proteins or DNA, previously grafted, adsorbed or embedded into the multilayered films [19,21-27,30,33].

In orthopaedic surgery, Geistlich Bio-Gide ${ }^{\mathrm{TM}}$ collagen membranes are currently used for guided bone regeneration and guided tissue regeneration. The success of this membrane is based on the natural bilayer structure, which contributes to excellent soft-tissue integration and optimal bone regeneration [34-36]. The objective of this study was to implement the multilayered nanostructures approach to equip those already used in the clinic devices with nanocontainers of active compounds capable of improving the rate of bone regeneration: chitosan $(\mathrm{CHI})$, a biocompatible polysaccharide with bone regenerative properties [37,38]; and BMP-2, a growth factor known to accelerate ECM production and bone tissue integration [39]. First, we inspected the build-up of our coating with quartz crystal microbalance with dissipation monitoring (QCM-D) and the structure and topography of our nanofibers by scanning electron microscopy (SEM). The potency of the BMP-2-loaded scaffolds with regards to bone regeneration was assessed both in vitro and in vivo.

\section{Methods}

Materials

CHI was purchased from Sigma (France) and Protasan up CL 113 was from FMC Biopolymer (Norway). DGL adendri-graft poly-L-lysine was purchased from Colcom (Montpellier, France). In this study, we used the fifth-generation $\mathrm{DGL}^{\mathrm{G} 5}$. Human recombinant BMP-2 was purchased from PeproTech (France). Bio-Gide collagen membranes was purchased from Proforma (Geistlich Bio-Gide $30 \times 40 \mathrm{~mm}$ ).

\section{Quartz crystal microbalance with dissipation monitoring}

QCM-D was operated with a D300 system (Q-Sense, Sweden) using a QAFC302 flow chamber and QSX301 gold-coated quartz crystal sensors. This technique consists of measuring the resonance frequency shifts $(\Delta f)$ and the dissipation factor changes $(\triangle D)$ of the quartz crystal sensor upon material deposition. The LbL build-up was performed by successive injections of polyelectrolyte or protein solutions $(500 \mu \mathrm{l})$ and rinsing solution $(500 \mu \mathrm{l})$ through the flow chamber and was monitored in situ. Changes in the resonance frequencies were measured at the third overtone $(v=3)$ corresponding to the $15-\mathrm{MHz}$ resonance frequency. A shift in
$\Delta f$ can be associated, in the first approximation, to a variation of the mass adsorbed onto the crystal through the Sauerbrey relationship: $m=-C \times \Delta f / v$. Where $C$ is a constant characteristic of the crystal used $\left(C=17.7 \mathrm{ng} \mathrm{cm}^{-2} \mathrm{~Hz}^{-1}\right)$. CHI $\left(500 \mu \mathrm{g} \mathrm{ml}^{-1}\right)$ and BMP-2 (200 $\left.\mathrm{ng} \mathrm{ml}^{-1}\right)$ were adsorbed by using 0.04 M MES ( $\mathrm{pH}: 5.5)$ and $0.15 \mathrm{M} \mathrm{NaCl}$ solutions.

\section{Build-up of the LbL films onto collagen membrane}

For all biological activity experiments, (CHI/BMP-2) 6 nanoarchitectures were builtup onto Bio-Gide scaffolds by the LbL method by alternating immersions during the $15 \mathrm{~min}$ in the adequate solutions $(300 \mu \mathrm{l})$ at the respective concentrations of $500 \mu \mathrm{g} \mathrm{ml} \mathrm{m}^{-1}$ for CHI and DGL ${ }^{\mathrm{G} 5}$ solutions and $200 \mathrm{ng} \mathrm{ml}^{-1}$ for the BMP-2 solutions in presence of $0.04 \mathrm{M}$ MES and $0.15 \mathrm{M} \mathrm{NaCl}$ at $\mathrm{pH}$ 5.5. After each deposition step, the membranes were rinsed for $15 \mathrm{~min}$ with $0.04 \mathrm{M}$ MES and $0.15 \mathrm{M} \mathrm{NaCl}$ at $\mathrm{pH} 5.5$. All membranes were sterilized for $30 \mathrm{~min}$ by exposure to UV light $(254 \mathrm{~nm}$; $30 \mathrm{~W}$; distance $20 \mathrm{~cm}$ ), and equilibrated in contact with $1 \mathrm{ml}$ of serum-free medium prior to cell culture.

\section{SEM observation}

For morphological study, the scaffolds were goldcoated (Edwards Sputter Coater ${ }^{\circledR}$, Edwards, Genevilliers, France) and observed with a Philips XL-30 ESEM ${ }^{\circledR}$ (Polymex, Fuveau, France) scanning electron microscope in conventional mode (high vacuum) with a Thornley-Everhart ${ }^{\circledR}$ (Polymex) secondary electron detector.

\section{Cell culture}

Human primary osteoblasts (HOB) were obtained from Cell Applications and cultured in Dulbecco's modified Eagle's medium (D-MEM $^{\circledR}$, Life Technologies, Saint Aubin, France) containing $50 \mathrm{U} \mathrm{ml}^{-1}$ penicillin, $50 \mu \mathrm{g}$ $\mathrm{ml}^{-1}$ streptomycin, $2.5 \mu \mathrm{g} \mathrm{ml} \mathrm{g}^{-1}$ amphotericin B and 10\% FBS (Life Technologies, Paisley, UK). The cells were incubated at $37^{\circ} \mathrm{C}$ in a humidified atmosphere of $5 \% \mathrm{CO}_{2}$. When cells reached subconfluence, they were harvested with trypsin and subcultured.

\section{In vitro cell viability \& proliferation}

Cell viability was determined by trypan blue exclusion. AlamarBlue ${ }^{\circledR}$ (Serotec, France) was used to assess cellular proliferation. The AlamarBlue test is a nontoxic, water-soluble, colorimetric redox indicator that changes color in response to cell metabolism. In this study, 
$2 \times 10^{4}$ human osteoblasts were seeded on top of LbL-coated 14-mm-diameter scaffolds $(\mathrm{n}=3)$ placed on 24-well plates. After 2 days of culture, cells were incubated in 10\% AlamarBlue/ DMEM solution in a humidified atmosphere at $37^{\circ} \mathrm{C}$ and $5 \% \mathrm{CO}_{2}$. After $4 \mathrm{~h}, 100 \mu \mathrm{l}$ of incubation media was transferred to 96 well plates and measured at $590 \mathrm{~nm}$ and $630 \mathrm{~nm}$ in order to determine the percentage of AlamarBlue reduction.

\section{- In vitro analysis of the mineralization using a fluorescent dye} Xylenol orange powder (Sigma) was dissolved in distilled water to make the $20 \mathrm{mM}$ stock solution. Xylenol orange was added to medium overnight to a final concentration of $20 \mu \mathrm{M}$. Before the microscopic examination, the samples were rinsed with fresh medium without fluorochrome to avoid nonspecific fluorescence. Xylenol orange expresses a red color under the fluorescent microscope (LEICA DM4000 B).

\section{- Immunofluorescence}

Collagen scaffolds with and without BMP-2 were seeded with $2 \times 10^{4} \mathrm{HOB}$ cells. After 21 days of culture in proliferation medium, cells were fixed with $4 \%$ PFA for $1 \mathrm{~h}$, rinsed three times with PBS, permeabilized with $0.1 \%$ Triton $\mathrm{X}-100$ for $1 \mathrm{~h}$, then rinsed three times with PBS. Indirect immunostaining was performed after the fixation. The primary antibody used was the rabbit polyclonal antioteopontin (1/600, Abcam, Paris, France) incubated for $20 \mathrm{~min}$ for bone detection. The secondary antibody was goat antirabbit conjugated to Alexa Fluor 488 (1/250, Invitrogen Molecular Probes, Eugene, USA) incubated overnight. After three rinses with PBS, cells were mounted on microscope slides using Vectashield (Vector Laboratories, Peterborough, UK) and imaged by a microscope equipped for fluorescence (LEICA DM4000B).

\section{- In vitro analysis of the mineralization using Alizarin Red S staining}

The samples were fixed with a solution of PFA $4 \%$ in PBS overnight at $4^{\circ} \mathrm{C}$. They were then dehydrated through a series of increasing ethanol concentrations, cleared with toluene and embedded in paraffin wax. Sections were cut at $7 \mu \mathrm{m}$ using a sledge microtome and mounted on glass slides. After the removal of paraffin wax, sections of the different samples were stained using Alizarin Red S (Sigma Aldrich). Alizarin Red $S$ powder was dissolved in distilled water in a
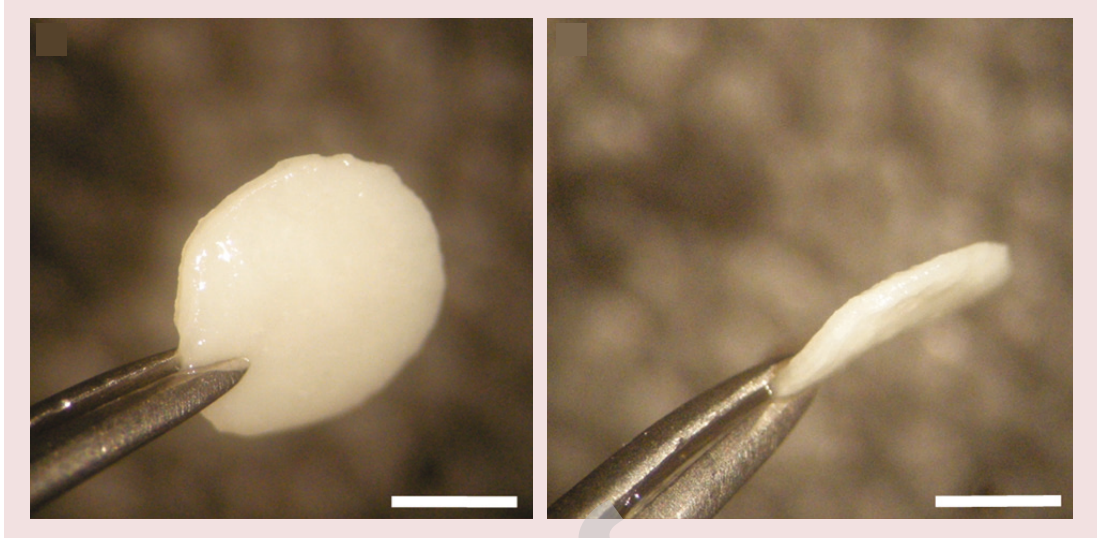

Figure 1. Macroscopic views of the Geistlich Bio-Gide ${ }^{\mathrm{TM}}$ collagen membranes currently used, in the clinic for bone regeneration. Scale bars: $2.5 \mathrm{~mm}$.

concentration of $2 \mathrm{~g}$ per $100 \mathrm{ml}$. The samples were incubated in the Alizarin Red solution for $20 \mathrm{~min}$ and then rinsed with distilled water several times. The sections were then observed under the optical microscope (LEICA DM4000 B).

\section{In vivo implantations}

In this study, nude mice were implanted on the skull. The mice were anesthetized with isofluorane gas and animals were placed on ventral decubitus on a heating table, with strict aseptic conditions after skin incision, two bony defects (5-mm size of bony defect) were performed using an electric drill with a sterile round bur under irrigation of sterile normal saline before deposition of two samples and sutures with Ethicon $9 / 0$. The skin was closed with sutures and the animal's behavior was observed after waking up. The mice were sacrificed with an intraperitoneal injection of a lethal dose of ketamine and the samples are extracted after 42 days of implantation. For all in vivo studies, male MF1-nu/nu
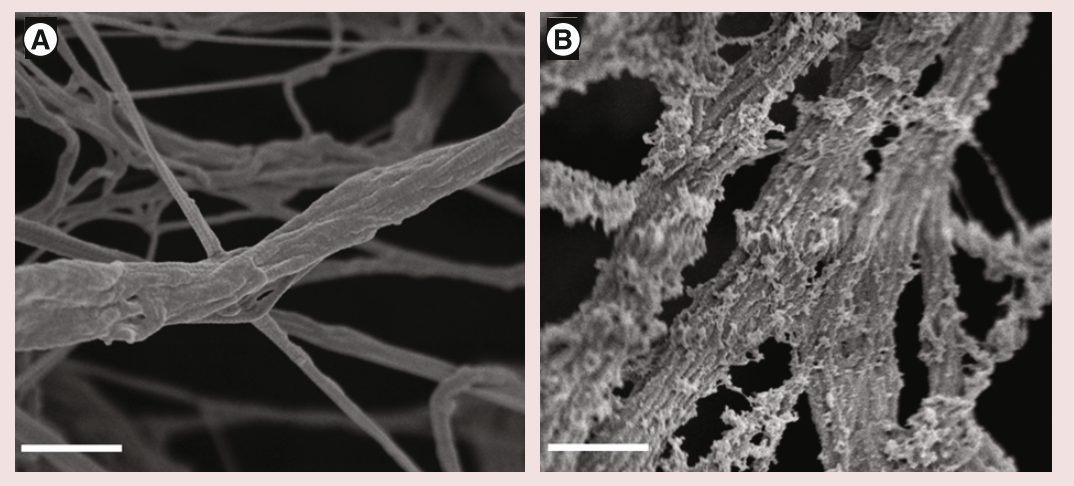

Figure 2. Scanning electron microscopy visualization of the Bio-Gide ${ }^{T M}$ collagen nanofibers. (A) Before treatment (native, not functionalized), and (B) after deposition of a (chitosan/BMP-2) ${ }_{6}$ architecture (functionalized). Scale bars: $1 \mu \mathrm{m}$. 


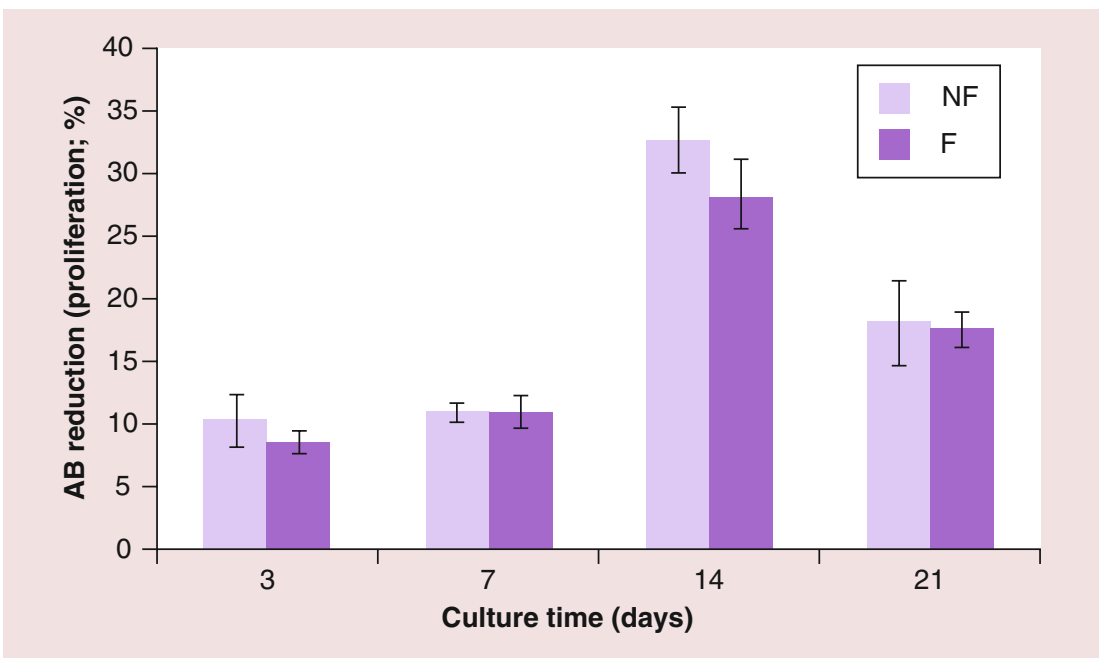

Figure 3. In vitro proliferation of human osteoblasts growing onto the native collagen nanofibers and onto the collagen nanofibers functionalized by (chitosan/BMP-2) ${ }_{6}$ nanoreservoirs (functionalized) after 3, 7, 14 and 21 days.

F: Functionalized by chitosan/BMP-2; NF: Not functionalized (native).

mice ( 5 weeks old, weight $30 \mathrm{~g}$ ) were purchased from Harlan (IL, USA) and acclimatized for a minimum of 1 week prior to experimentation. All procedures were performed with prior received ethical approval and carried out in accordance with the regulations laid down for animals.

\section{Histological examination of bone regeneration using Mallory coloration The implants were fixed with BouinHollande solution for 2 days. Then, they were dehydrated through a series of increasing ethanol concen- trations, cleared with toluene and embedded in paraffin wax. Sections were cut at $7 \mu \mathrm{m}$ using a sledge microtome and mounted on glass slides. After the removal of paraffin wax, the sections were stained using Mallory coloration for 2 days.}
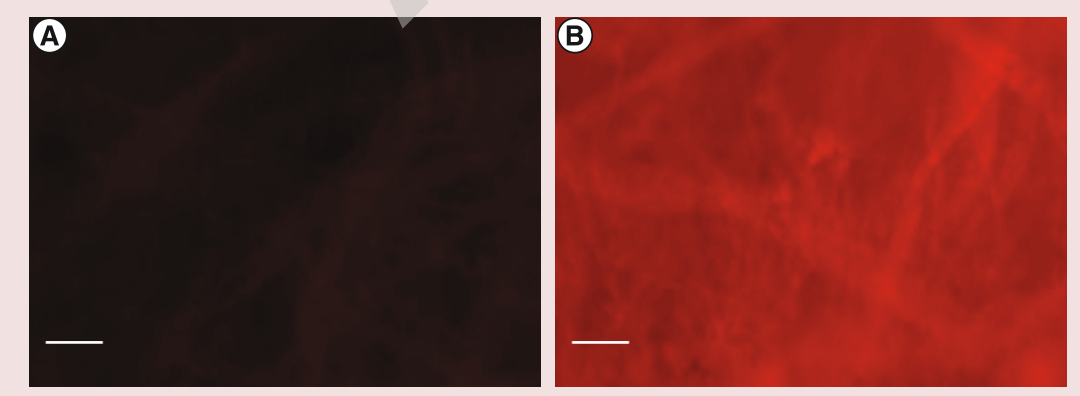

Figure 4. Calcium deposit analysis. Xylenol orange detection (in red) of calcium deposit on the collagen nanofibers after 21-day incubation of human osteoblasts (A) before and (B) after functionalization with (chitosan/BMP-2) ${ }_{6}$ nanocontainers. Intensity average quantification: (A) $22.5 \pm 2.3$ and (B) $51.2 \pm 4.1$. We have an increase of $23 \%$ of bone mineralization by using the functionalized implant in the presence of chitosan/BMP-2 compared with the native implant. Scale bars: $50 \mu \mathrm{m}$.
Confocal Raman microspectroscopy After 42-day implantation into mouse calvaria, the implants were explanted, rinsed with PBS, fixed with PFA $4 \%$ for $24 \mathrm{~h}$ at $4^{\circ} \mathrm{C}$, then rinsed three times and stored in PBS. Prior to Raman analysis, the implants were briefly rinsed with water and dried under a gentle flow of argon. Raman measurements were carried out in air using a confocal Raman microspectrometer composed of a Raman spectrometer (LabRam $\mathrm{HR}^{\circledR}$ [Horiba Scientific, Neuhausen, Germany] by Jobin-Yvon Horiba with a 600 line $\mathrm{mm}^{-1}$ grating) coupled to a microscope (Model BX41, Olympus, France) with $x y z$ mapping stage via optical fibers. The excitation of Raman scattering was operated with a helium-neon laser at a wavelength of $632.8 \mathrm{~nm}$. The laser beam was focused on the sample by means of a $\times 50$ LWD microscope objective. Confocal pinholes of $400 \mu \mathrm{m}$ diameter for single spectra and $250-\mu \mathrm{m}$ diameter for $2 \mathrm{D}$ mappings placed before the entrance slit were used to reject Raman signal from out-offocus planes. Raman spectra with a good signalto-noise ratio were recorded with an integration time of $60 \mathrm{~s}$ for single spectra and $20 \mathrm{~s}$ for $2 \mathrm{D}$ mappings.

\section{Results \& discussion}

Recently, we have reported on the effective incorporation of BMP-2 into (DGL $\left.{ }^{\mathrm{G} 5} / \mathrm{BMP}-2\right)_{6}$ LbL architectures with DGL, a dendrigraft of poly-L-lysine [39]. The mean amount of hydrated BMP-2 growth factor immobilized was approximately $1.53 \mu \mathrm{g} \mathrm{cm}^{-2}$. Here, we have used US FDA-approved CHI as polycationic polysaccharide to incorporate the BMP-2 into the nanostructured coatings. $\mathrm{CHI}$ is derived from chitin, a polysaccharide found in the exoskeleton of shellfish such as shrimps, lobsters and/or crabs. The effective build-up of (CHI/BMP-2) n LbL architectures onto gold-coated substrates was demonstrated by QCM-D up to six adsorption cycles. It followed a linear growth regimen with deposited mass increments of approximately $1.1 \mu \mathrm{g} \mathrm{cm}^{-2}$ corresponding to $10 \mathrm{~nm}$ in equivalent uniform thickness upon each new deposited CHI/BMP-2 layer pair. The mean amount of hydrated BMP-2 growth factor immobilized was approximately $0.73 \mu \mathrm{g} \mathrm{cm}^{-2}$, which is twofold lower than with $\mathrm{DGL}^{\mathrm{G} 5}$. This must be due to more efficient interactions of the protein with the dendritic structure of DGL ${ }^{\mathrm{G} 5}$ than with the linear structure of CHI. Our ultimate goal is to propose this new implant as a unique active medical device, we have chosen the FDA-approved $\mathrm{CHI}$ and not DGL. After SEM analysis of the 
nanofiber collagen implant before and after the coating, we have preferred to functionalize the implants by (CHI-BMP-2) ${ }_{6}$ and not (CHIBMP-2) ${ }_{3}$, showing more homogeneity of the coating.

The aim of this work is to functionalize active collagen membrane by active nanocontainers that are able to increase the speed of bone regeneration. The effective deposition, and nanoscale dimensions, of the bioactive coating onto Bio-Gide collagen membranes (Figure 1) were confirmed by means of SEM. While the native nanofibers displayed a smooth topography (Figure 2A), (CHI/BMP-2) ${ }_{6}$-treated nanofibers were coated with uniformly distributed 'fish scale'-like nanostructured deposits (Figure 2B). Interestingly, this open fish scale-like morphology was very different from the compact spheroid morphology of (DGL $55 / B M P-2)_{6}$ deposits obtained both on collagen membranes and on poly- $\varepsilon$-caprolactone (PCL) membranes [39]. Distinct morphologies can be explained by the low flexibility/high persistence length (6-12 nm) of CHI chains [40], limiting the interactions with BMP-2, while the high flexibility/low persistence length $(2 \mathrm{~nm})$ of poly-Llysine chains of DGL allows optimized interactions with BMP-2 [41].

In order to explore the capacity of the modified collagen membranes to induce bone formation in vitro, we have first compared the adhesion of human osteoblasts onto native or (CHI/BMP-2) 6 -treated collagen implants. In line with recently published data $[42,43]$, morphology changes between cells adhering onto native and LbL-treated collagen scaffolds were likely to be due to the combined modifications of both the surface chemistry and the nanotopography upon the LbL treatment (data not shown).

We then followed the proliferation and cell activity of human osteoblasts for 21 days onto (CHI/BMP-2) ${ }_{6}$-treated collagen implants compared with native implants (Figure 3). Our results showed similar cell behavior for both the functionalized and not collagen membranes (Figure 3), reaching a peak value at day 14 . Cell activity then significantly decreased between day 14 and day 21 for both types of substrate. This fall down in proliferation and cell activity, at this stage, is certainly due to the osteoblasts undergoing differentiation to produce their own biomineralized ECM. We have also shown that after 21 days of culture, the proliferation decreased dramatically due to the mineralization at this stage (Figure 4). Therefore, at 42 days we are unable to follow the proliferation. These results
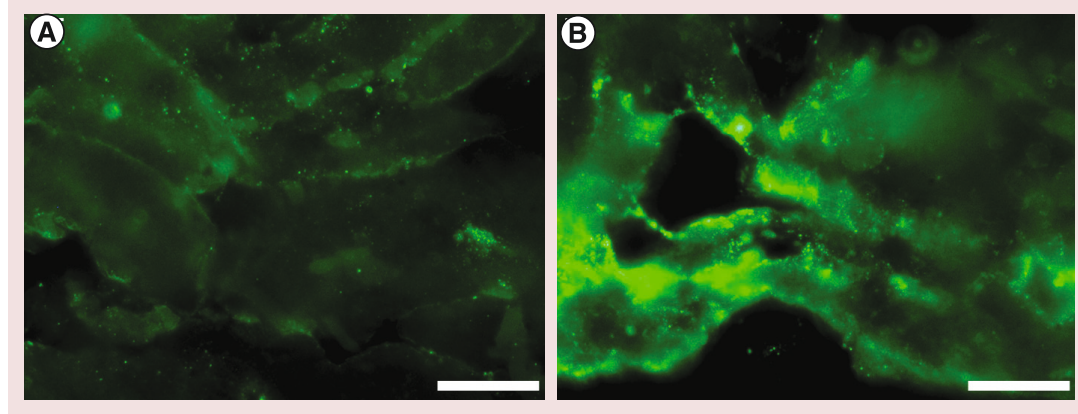

Figure 5. Osteopontin expression (in green) in primary osteoblasts cells cultured for 21 days on (A) nonfunctionalized collagen membrane and (B) functionalized (chitosan/BMP-2) ${ }_{6}$-treated collagen membrane. No osteopontin induction was detected by using (chitosan/BSA) ${ }_{6}$-treated collagen membrane as a negative control. Scale bars: $20 \mu \mathrm{m}$.

show that the functionalization of the collagen implants with (CHI/BMP-2) ${ }_{6}$ nanocontainers did not impair the cell activity.

In order to assess the improvement of in vitro bone formation induced by primary osteoblasts in contact with the BMP-2 nanocontainers, we compared the extent of calcium depositions onto the native collagen implant and (CHI/BMP-2) -treated membranes in the presence of primary osteoblasts. In this study, Xylenol orange fluorescence used as staining for the specific calcium depositions clearly indicated more mineralization onto (CHI/BMP-2) ${ }_{6}$-treated collagen scaffolds than onto the native scaffold (Figure 4). After an intensity average quantification $(22.5 \pm 2.3$ (Figure 4A) and $51.2 \pm 4.1$ (Figure 4B)), we have shown an increase of $23 \%$ of bone mineralization by using the functionalized implant (CHI/BMP-2) compared with the native implant. We have also analyzed by immunochemistry the capacity of these nanoreservoirs, in the presence of human osteoblasts, to induce in vitro-specific

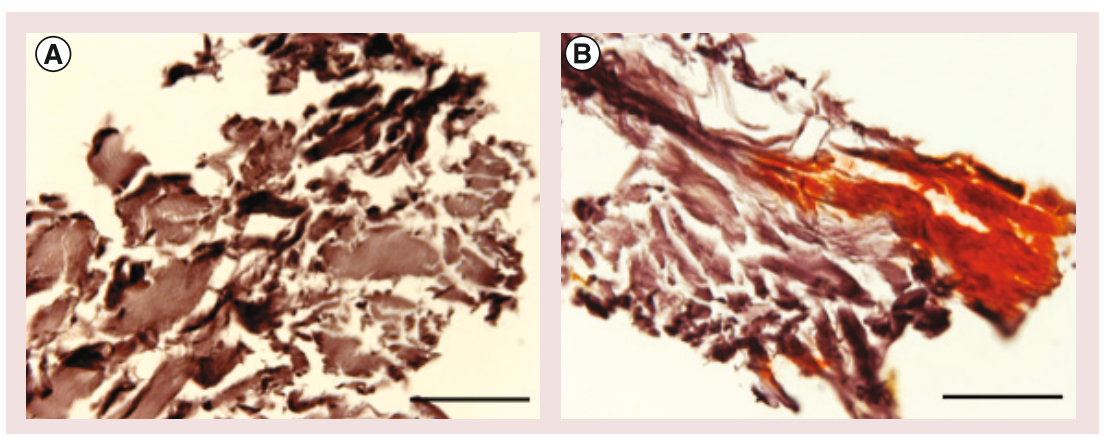

Figure 6. Alazarin Red detection of bone mineralization. Alizarin Red detection of calcium depositions on the collagen nanofibers after 21-days incubation of human osteoblasts (A) before and (B) after functionalization with (chitosan/BMP-2) ${ }_{6}$ nanocontainers. No calcium deposition was detected after 21 days of culture on the native collagen membrane without BMP-2. Scale bars: $100 \mu \mathrm{m}$. 


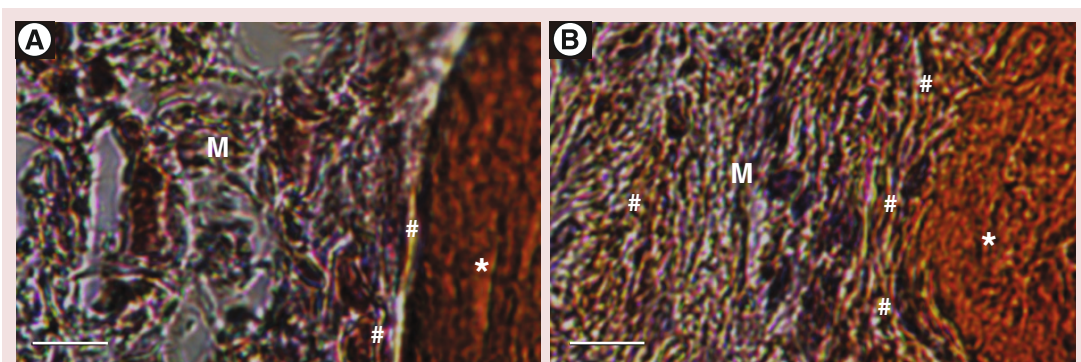

Figure 7. Histological analysis of bone induction. Histological analysis and the detection of bone induction after 42 days in vivo implantation on skull of nude mice of the (A) native collagen implant and the (B) functionalized collagen implant by the active nanoreservoirs of (chitosan/BMP-2) 6 . Blue areas show cell colonization. Scale bars: $25 \mu \mathrm{m}$

*: Host bone (orange/red); \#: New mineralized matrix (yellow); M: Collagen membrane nanofibers; osteopontin expression after 21 days of culture (Figure 5). This result strongly suggests that the entrapment of BMP-2 into fish scale-like CHIbased LbL nanocontainers preserved its accessibility to osteoblast cells, as well as its ability to increase and accelerate the mineralization of the ECM produced by the osteoblasts. For more in vitro analysis, we have also followed by Alizarin Red detection the calcium deposition on the collagen nanofibers after 21 days incubation of human osteoblasts before and after functionalization with (CHI/BMP-2) ${ }_{6}$ nanoreservoirs, and shown calcium deposition when functionalized by BMP-2 (orange detection) and no deposition on the native collagen implant (Figure 6).

After the in vitro bone induction, we also analyzed the potential of our active implants to induce bone regeneration in vivo. A native collagen implant and a (CHI/BMP-2) ${ }_{6}$-treated implant were implanted into mouse calvaria defects for 42 days. The histological study was then carried out to observe the scaffold colonization by the host cells in the bone defect site, the osseointegration and the new bone mineralization. Mallory coloration was used in order to distinguish between mineralized bone, ECM and nuclear cell (Figure 7). The results clearly indicate excellent osseointegration of both (CHI/BMP-2) ${ }_{6}$-treated and untreated collagen membranes, with slightly better results for the treated implant (Figure 7B). Colonization and migration of osteoblasts from the site of implantation within both implants clearly occurred, as shown by the fibrous aspect of the samples filled with native osteoblasts. However, the (CHI/ BMP-2) ${ }_{6}$-treated collagen implant appears to be more cohesive and shows the formation of an ECM undergoing mineralization (Figure 7B).

The bone mineralization of a native collagen implant, and a (CHI/BMP-2) ${ }_{6}$-treated collagen implant after 42-day implantation in calvaria was also inspected by confocal Raman microspectroscopy, to detect calcium phosphate $(\mathrm{CaP})$ deposition (Figure 8). In this study, we have also analyzed, as a control, a treated implant by using a dendrigraft of L-lysine $\left(\mathrm{DGL}^{\mathrm{G} 5}\right.$ ) instead of CHI. These implants were also implanted and analyzed in order to test the versatility of the LbL method for embedding BMP-2 onto the collagen proposed new device. The Raman signatures were very similar for all the implanted scaffolds, except for the bands at $430-450 \mathrm{~cm}^{-1}\left(v_{2} \mathrm{PO}_{4}{ }^{3-}\right), 580-610 \mathrm{~cm}^{-1}$ $\left(v_{4} \mathrm{PO}_{4}^{3-}\right), 962 \mathrm{~cm}^{-1}\left(v_{1} \mathrm{PO}_{4}^{3-}\right)$ and $1072 \mathrm{~cm}^{-1}$ $\left(v_{1} \mathrm{CO}_{3}^{2-}\right.$ and $\left.v_{3} \mathrm{PO}_{4}^{3-}\right)$, which, promisingly, are relative to $\mathrm{B}$-type carbonated hydroxyapatite $\left(\mathrm{PO}_{4}{ }^{3-}\right.$ substituted by $\left.\mathrm{CO}_{3}{ }^{2}\right)$, the major mineral component of bone (Figure 8) [44,45]. 2D mappings of the $962-\mathrm{cm}^{-1}$ Raman peak intensity of B-type carbonated hydroxyapatite revealed extensive in vivo mineralization over both (CHI/BMP-2) ${ }_{6}$ - and (DGL $\left.55 / B M P-2\right)_{6}$-treated scaffolds, while no trace of mineralization was found atop the untreated implant after 42 days implantation (Figure 8). These results support the promising effect of BMP-2-based nanocontainer deposits on the biomineralization of the implants. In line with our previous work with PCL nanofibrous implants [39], DGL ${ }^{65}$-based nanoreservoirs of BMP-2 was confirmed here to be a versatile and efficient strategy to induce bone formation. CHI-based nanoreservoirs of BMP-2 show similar results in terms of biomineralization in vivo, and seem, to us, to be more promising in the short-/mid-term because CHI is an FDA-approved component, while DGL ${ }^{\mathrm{G}}$ is not yet. In addition, although $\mathrm{DGL}^{\mathrm{G} 5}$ was shown to allow higher loading of the nanoreservoirs with BMP-2 than CHI, as seen before, the amount of growth factor immobilized by means of CHI is sufficient to reach the same extent of implant biomineralization. This can be due to the open fish scale-like morphology of CHI-based nanoreservoirs allowing easier degradation, and thus offering better accessibility to BMP-2 to the cells than the compact spheroid morphology of $\mathrm{DGL}^{\mathrm{G} 5}$-based nanoreservoirs [39].

\section{Conclusion}

At this stage, our results show that we can functionalize a collagen implant already used in the clinic with nanocontainers of BMP-2 made by CHI (FDA approved), induce bone formation in vitro and in vivo, and accelerate the speed of bone regeneration in vivo. 
The European and American authorities have already approved the use of BMP-2 for bone regeneration applications. For example, Medtronic offers InductOSTM (Medtronic, Boulogne-Billancourt, France), which is a basic collagen matrix soaked in BMP-2. The efficacy of this kind of combination device is dependent on slow release kinetics for BMPs, which is recognized as the critical, most challenging requirement for combination implants. For efficient bone regeneration, the target cells require a reliable and continuous exposure to growth factors over an extended period of time, until the induction of new bone. However, degradation of BMP-2 occurs rapidly in aqueous solution. With current systems using collagen matrices soaked with the growth factor, this problem is addressed by overdosing, which may induce adverse side effects. The novelty of our approach lies in the nanoimmobilization of BMP-2. The nanostructured scaffold is produced by the LbL technology, which allows to be entrapped the growth factor into nanocontainers atop the scaffold fibers. Recently, we have elucidated the mechanism by which cells come in to contact and interact with such nanostructured coating [19,43]. Encapsulated by polymers, BMP-2 is likely to be protected and stabilized. Once cells come into contact with the deposits, cellular enzymes degrade this polymer coating and BMP-2 becomes available. As cells grow, divide and infiltrate deeper into the porous structure of the membrane, they provoke a slow and progressive release of BMP-2 that, in turn, further stimulates the biomineralization of the ECM. This strategy aims to considerabley enhance therapeutic efficacy and should lead to implants that are capable, at a reduced cost, of more robust and durable bone repair in large defects compared with current less sophisticated approaches.

\section{Future perspective}

Over the next decades, new therapeutics based on nanotechnology could offer significant opportunities to revolutionize medicine. On the other hand, if nanomedicine wants to realize its full potential, some major legal and economic obstacles have to be removed. Here, we describe active living collagen implants with highly promising bone regenerative properties. Our nanotechnology approach allows protective encapsulation as a nano 'fish scales' like of active growth factor. This strategy may be used as a new design reflection for a future generation of smart implants for regenerative nanomedicine application.
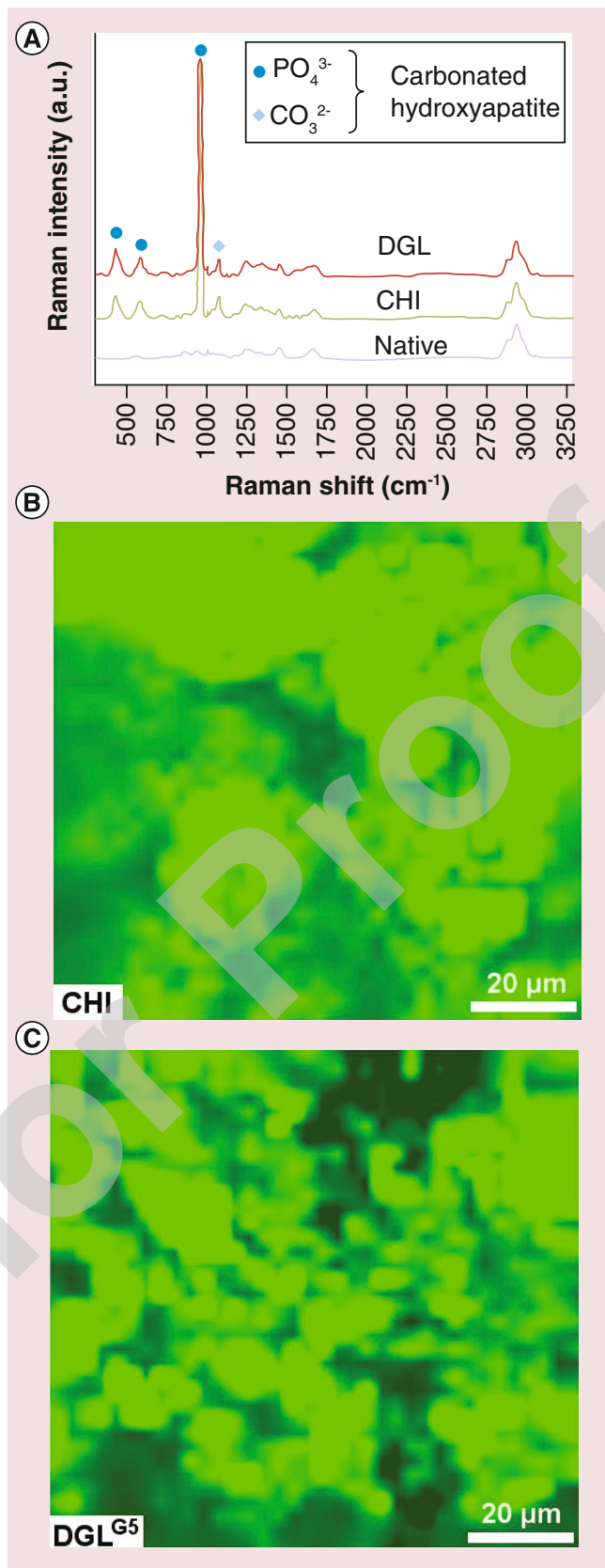

Figure 8. Raman analysis of native (chitosan/BMP-2) ${ }_{6}$-treated and (DGL $\left.{ }^{\mathrm{G}} / \mathrm{BMP}-2\right)_{6}$-treated collagen implants after 42-day implantation in mouse calvaria. (A) Typical Raman spectra showing the biomineralization of calcium phosphate within the form of carbonated hydroxyapatite over both BMP-2-enriched implants, and not over the native implant. Spectra were offset for the sake of clarity. (B \& C) 2D mapping of the $962 \mathrm{~cm}^{-1}$ Raman peak of carbonated hydroxyapatite over the BMP-2-enriched implant $\left(100 \times 100 \mu \mathrm{m}^{2}\right.$; mesh size $\left.2.8 \mu \mathrm{m}\right)$.

\section{Acknowledgements}

The authors thank MF Rubner from the Department of Materials Science and Engineering, Massachusetts Institute of Technology (MA, USA), for helpful scientific discussions. 


\author{
Financial \& competing interests disclosure \\ This work was supported by the project Nano OSCAR from \\ the 'Agence Nationale de la Recherche, ANR'. N \\ Benkirane-Jessel is indebted to CHU de Nancy, Hôpital \\ Central, 'Chirurgie Orthopédique et Traumatologie'(Con- \\ trat d'interface INSERM vers l'hôpital). G Ladamc thanks \\ the 'Grand Evreux Agglomération' and the 'Conseil Général
}

de l'Eure' for partial financial support of La2B. The authors have no other relevant affiliations or financial involvement with any organization or entity with a financial interest in or financial conflict with the subject matter or materials discussed in the manuscript apart from those disclosed.

No writing assistance was utilized in the production of this manuscript.

\section{Executive summary}

- We report on active collagen implants equipped by nanocontainers of BMP-2 for regenerative nanomedicine.

- The sophisticated strategy described here should enhance the efficacy of therapeutic implants compared with current simplistic approaches soaked with BMP-2.

- Our nanotechnology approach allows protective encapsulation as a nanoreservoir of growth factor.

- We believe that we can develop safer and more effective new-based nanomedicines in a cost effective and efficient manner. - This strategy may serve as a design reflection for biologically inspired materials technologies.

\section{References}

1 Farokhzad OC, Langer R. Nanomedicine: developing smarter therapeutic and diagnostic modalities. Adv. Drug Deliv. Rev. 58(14), 1456-1459 (2006).

2 Liu Y, Miyoshi H, Nakamura M. Nanomedicine for drug delivery and imaging: a promising avenue for cancer therapy and diagnosis using targeted functional nanoparticles. Int. J. Cancer 120 (12), 2527-2537 (2007).

3 Caruthers SD, Wickline SA, Lanza GM. Nanotechnological applications in medicine. Curr. Opin. Biotechnol. 18(1), 26-30 (2007).

4 Wagner V, Dullaart A, Bock AK, Zweck A. The emerging nanomedicine landscape. Nat. Biotechnol. 24(10), 1211-1217 (2006).

5 Peppas NA, Langer R. New challenges in biomaterials. Science 263(5154), 1715-1720 (1994).

6 Hubbell JA. Biomaterials in tissue engineering. Biotechnology (NY) 13(6), 565-576 (1995).

7 Langer R, Tirrell DA. Designing materials for biology and medicine. Nature 428(6982), 487-492 (2004).

8 Griffith LG, Naughton G. Tissue engineering - current challenges and expanding opportunities. Science 295(5557), 1009-1014 (2002).

9 Chaikof EL, Matthew H, Kohn J, Mikos AG, Prestwich GD, Yip CM. Biomaterials and scaffolds in reparative medicine. Ann. $N Y$ Acad. Sci. 961, 96-105 (2002).

10 Yang C, Hillas PJ, Baez JA et al. The application of recombinant human collagen in tissue engineering. BioDrugs 18(2), 103-119 (2004).

11 Kumar G, Tison CK, Chatterjee K et al. The determination of stem cell fate by $3 \mathrm{D}$ scaffold structures through the control of cell shape. Biomaterials 32 (35), 9188-9196 (2011).
12 Pullela SR, Andres C, Chen W, Xu C, Wang L, Kotov NA. Permselectivity replication of artificial glomerular basement membranes in nanoporous collagen multilayers. J. Phys. Chem. Lett. 2(16), 2067-2072 (2011).

13 Lee J, Cuddihy MJ, Kotov NA. Three-dimensional cell culture matrices: state of the art. Tissue Eng. Part B Rev. 14(1), 61-86 (2008).

14 Dvir T, Timko BP, Kohane DS, Langer R. Nanotechnological strategies for engineering complex tissues. Nat. Nanotechnol. 6(1), 13-22 (2010).

15 Park KI, Teng YD, Snyder EY. The injured brain interacts reciprocally with neural stem cells supported by scaffolds to reconstitute lost tissue. Nat. Biotechnol. 20(11), 1111-1117 (2002).

16 Choi JH, Park YW, Park TH et al. Fuzzy nanoassembly of polyelectrolyte and layered clay multicomposite toward a reliable gas barrier. Langmuir 28(17), 6826-6831 (2012).

17 Wang D, Rogach AL, Caruso F. Semiconductor quantum dot-labeled microsphere bioconjugates prepared by stepwise self-assembly. Nano. Lett. 2(8), 857-861 (2002).

18 Berth G, Voigt A, Dautzenberg H, Donath E, Mohwald H. Polyelectrolyte complexes and layer-by-layer capsules from chitosan/chitosan sulfate. Biomacromolecules 3(3), 579-590 (2002).

19 Jessel N, Atalar F, Lavalle P et al. Bioactive coatings based on a polyelectrolyte multilayer architecture functionalized by embedded proteins. Adv. Mater. 15(9), 692-695 (2003)

20 Hiller J, Mendelsohn JD, Rubner MF. Reversibly erasable nanoporous anti-reflection coatings from polyelectrolyte multilayers. Nat. Mater. 1(1), 59-63 (2002).

21 Benkirane-Jessel N, Schwinte P, Falvey P et al. Build-up of polypeptide multilayer coatings with anti-inflammatory properties based on the embedding of piroxicam-cyclodextrin complexes. $A d v$. Funct. Mater. 14(2), 174-182 (2004).

22 Jessel NB, Schwinte P, Donohue R et al. Pyridylamino-beta-cyclodextrin as a molecular chaperone for lipopolysaccharide embedded in a multilayered polyelectrolyte architecture. Adv. Funct. Mater. 14(10), 963-969 (2004).

23 Benkirane-Jessel N, Lavalle P, Hubsch E et al. Short-time tuning of the biological activity of functionalized polyelectrolyte multilayers. Adv. Funct. Mater. 15(4), 648-654 (2005).

24 Gangloff SC, Ladam G, Dupray V et al. Biologically active lipid $\mathrm{A}$ antagonist embedded in a multilayered polyelectrolyte architecture. Biomaterials 27(9), 1771-1777 (2006).

25 Jessel N, Oulad-Abdelghani M, Meyer F et al. Multiple and time-scheduled in situ DNA delivery mediated by beta-cyclodextrin embedded in a polyelectrolyte multilayer. Proc. Natl Acad. Sci. USA 103(23), 8618-8621 (2006).

26 Dierich A, Le Guen E, Messaddeq N et al. Bone formation mediated by synergy-acting growth factors embedded in a polyelectrolyte multilayer film. Advanced Materials 19(5), 693-697 (2007).

27 Zhang X, Sharma KK, Boeglin M et al. Transfection ability and intracellular DNA pathway of nanostructured gene-delivery systems. Nano Lett. 8(8), 2432-2436 (2008).

28 Facca S, Cortez C, Mendoza-Palomares C et al. Active multilayered capsules for in vivo bone formation. Proc. Natl Acad. Sci. USA 107(8), 3406-3411 (2010).

29 Lee J, Kotov NA. Notch ligand presenting acellular 3D microenvironments for ex vivo human hematopoietic stem-cell culture made by layer-by-layer assembly. Small 5(9), 1008-1013 (2009). 
30 Shim BS, Podsiadlo P, Lilly DG et al. Nanostructured thin films made by dewetting method of layer-by-layer assembly. Nano Lett. 7(11), 3266-3273 (2007).

31 Macdonald M, Rodriguez NM, Smith R, Hammond PT. Release of a model protein from biodegradable self assembled films for surface delivery applications. J. Control Release 131(3), 228-234 (2008).

32 MacDonald Ml, Samuel RE, Shah NJ, Padera RF, Beben YM, Hammond PT. Tissue integration of growth factor-eluting layer-by-layer polyelectrolyte multilayer coated implants. Biomaterials 32(5), 1446-1453 (2011).

33 Shah NJ, Macdonald ML, Beben YM, Padera RF, Samuel RE, Hammond PT. Tunable dual growth factor delivery from polyelectrolyte multilayer films. Biomaterials 32(26), 6183-6193 (2011).

34 Rothamel D, Schwarz F, Sculean A, Herten M, Scherbaum W, Becker J. Biocompatibility of various collagen membranes in cultures of human PDL fibroblasts and human osteoblast-like cells. Clin. Oral Implants Res. 15(4), 443-449 (2004).
35 Zitzmann NU, Naef R, Scharer P. Resorbable versus nonresorbable membranes in combination with Bio-Oss for guided bone regeneration. Int. J. Oral Maxillofac. Implants 12(6), 844-852 (1997).

36 Schwarz F, Rothamel D, Herten M et al. Immunohistochemical characterization of guided bone regeneration at a dehiscence-type defect using different barrier membranes: an experimental study in dogs. Clin. Oral Implants Res. 19(4), 402-415 (2008).

37 Di Martino A, Sittinger M, Risbud MV. Chitosan: a versatile biopolymer for orthopaedic tissue-engineering. Biomaterials 26(30), 5983-5990 (2005).

38 Kim IY, Seo SJ, Moon HS et al. Chitosan and its derivatives for tissue engineering applications. Biotechnol. Adv. 26(1), 1-21 (2008).

39 Mendoza-Palomares C, Ferrand A, Facca S et al. Smart hybrid materials equipped by nanoreservoirs of therapeutics. ACS Nano 6(1), 483-490 (2012).

40 Cölfen H, Berth G, Dautzenberg H. Hydrodynamic studies on chitosans in aqueous solution. Carbohydr. Polym. 45(4), 373-383 (2001).

41 Brant DA, Flory PJ. The configuration of random polypeptide chains. I. Experimental results. J. Am. Chem. Soc. 87(13), 2788-2791 (1965).

42 Anselme K, Davidson P, Popa AM, Giazzon M, Liley M, Ploux L. The interaction of cells and bacteria with surfaces structured at the nanometre scale. Acta Biomater. 6(10), 3824-3846 (2010).

43 Wheeldon I, Farhadi A, Bick AG, Jabbari E, Khademhosseini A. Nanoscale tissue engineering: spatial control over cell-materials interactions. Nanotechnology 22(21), 212001 (2011).

44 Penel G, Leroy G, Rey C, Bres E. MicroRaman spectral study of the PO4 and $\mathrm{CO} 3$ vibrational modes in synthetic and biological apatites. Calcif. Tissue Int. 63(6), 475-481 (1998).

45 Crane NJ, Popescu V, Morris MD, Steenhuis P, Ignelzi MA. Raman spectroscopic evidence for octacalcium phosphate and other transient mineral species deposited during intramembranous mineralization. Bone 39(3), 434-442 (2006). 